\title{
The role of antibiotic-loaded bone cement in complicated knee arthroplasty: relevance of gentamicin allergy and benefit from revision surgery - a case control follow-up study and algorithmic approach
}

Benjamin Thomas ${ }^{1,2^{*}}$ (D), Maria Benedikt ${ }^{1,3}$, Ali Alamri ${ }^{1}$, Florian Kapp ${ }^{1}$, Rainer Bader ${ }^{4}$, Burkhard Summer ${ }^{1}$, Peter Thomas ${ }^{1}$ and Eva Oppel ${ }^{1}$

\begin{abstract}
Background: Antibiotic-loaded (particularly gentamicin) bone cement (BC) is widely used in total joint arthroplasty (TJA) to prevent periprosthetic infections (PPIs), but may itself cause implant failure. In light of a complete lack in literature, the objective was to assess the clinical relevance of gentamicin allergy for failure of cemented total knee arthroplasties in 25 out of 250 patients with positive patch test reactions to gentamicin and otherwise unexplained symptoms by evaluating benefits from revision with change to gentamicin-free cement.

Methods: Fifteen of these 25 patients and their treating orthopaedic surgeons agreed to a re-assessment. They were surveyed regarding interim course of therapy and symptoms, including re-assessment of the Knee Injury and Osteoarthritis Outcome Score (KOOS), and underwent follow-up clinical and radiographic investigations. The initial use of gentamicin-loaded BC was reaffirmed by review of the primary implantation operative reports and respective implant passports. Primary and follow-up KOOS scores were analyzed regarding benefits from revision surgery by comparing nine patients with revision to six without revision.

Results: Mean follow-up time was 38 months. The entirety of patients experienced an improvement of selfreported symptoms, with revision surgery (i.e., switching to gentamicin-free BC or uncemented total knee arthroplasty) yielding significantly greater improvement $(p=0.031)$ : the nine revised patients reported a significant symptom relief ( $p=0.028)$, contrary to the six unrevised patients $(p=0.14)$. Interestingly, the decision to proceed with revision surgery was significantly correlated with higher symptom severity $(p=0.05)$.
\end{abstract}

Conclusion: In symptomatic total knee arthroplasty with gentamicin allergy, uncemented revision arthroplasty or change to gentamicin-free BC provides significant symptom relief.

Keywords: Gentamicin, Bone cement, Allergy, Total knee arthroplasty, Implant failure, Revision

\footnotetext{
*Correspondence: benjamin.felix.thomas@gmail.com

${ }^{1}$ Department of Dermatology and Allergology, Ludwig-Maximilians-University

Munich, Frauenlobstrasse 9-11, 80337 Munich, Germany

${ }^{2}$ Department of Hand, Plastic, and Reconstructive Surgery, Burn Center, BG

Trauma Center, University of Heidelberg, Ludwig-Guttmann-Strasse 13, 67071 Ludwigshafen, Germany

Full list of author information is available at the end of the article
}

(c) The Author(s). 2020 Open Access This article is licensed under a Creative Commons Attribution 4.0 International License, which permits use, sharing, adaptation, distribution and reproduction in any medium or format, as long as you give appropriate credit to the original author(s) and the source, provide a link to the Creative Commons licence, and indicate if changes were made. The images or other third party material in this article are included in the article's Creative Commons licence, unless indicated otherwise in a credit line to the material. If material is not included in the article's Creative Commons licence and your intended use is not permitted by statutory regulation or exceeds the permitted use, you will need to obtain permission directly from the copyright holder. To view a copy of this licence, visit http://creativecommons.org/licenses/by/4.0/. The Creative Commons Public Domain Dedication waiver (http://creativecommons.org/publicdomain/zero/1.0/) applies to the data made available in this article, unless otherwise stated in a credit line to the data. 


\section{Background}

Total joint replacement (TJR) is efficient and successful in the treatment of degenerative and inflammatory joint disorders: TJR can restore joint function, alleviate pain, and help regain quality of life. Therefore, total hip (THR) and knee replacement (TKR) have been acknowledged as the gold standard in advanced symptomatic osteoarthritis of the hip and knee joint. Today, approximately one million TJRs are implanted in the USA per year, with numbers projected to quadruple within the next two decades $[1,2]$. However, there is a serious, yet frequent drawback to this success story: 9\% of all TJR surgeries are complication-related revisions [3]. With an annual incidence of 1 to $3 \%$, periprosthetic infection (PPI) brings about particularly poor clinical outcomes and technically difficult revision surgery $[4,5]$. Moreover, the treatment costs of PPIs increase fourfold compared to primary implantations [6]. Alarmingly, the annual economic burden of infectious joint revisions is projected to exceed $\$ 1.5$ billion by the end of 2019 [7]. Understandably, many attempts have been undertaken to reduce the incidence of PPIs, such as administering systemic antibiotics, or the use of antibiotic-loaded bone cement (ALBC).

Nowadays, poly-methylmethacrylate (PMMA)-based bone cement $(\mathrm{BC})$ is the most widely used antibiotic vehicle in this context. This $\mathrm{BC}$ comprises a two-part system composed of a powdery and a liquid component. The former contains an acrylic MMA-polymer and an initiator (e.g., benzyl peroxide [BPO]) to start the redox polymerization, and the latter contains an acrylic MMAmonomer, an activator to maintain the polymerization reaction (e.g., N,N-dimethyl-p-toluidine [DMPT]), and a stabilizer to prevent premature curing (e.g., hydroquinone) $[8,9]$. Based on the premise of enhanced prostheses fixation and prophylactic antibiotic delivery, standard use of ALBC has been common practice in the UK [10,11], Scandinavia [12], and Germany [13]. On the contrary, despite representative polls reporting an increasing use of primary prophylactic ALBC [14], the majority of orthopaedic surgeons in the USA remain skeptical [15].

Regarding the assumption of increased arthroplasty fixation, the literature is inconclusive for cementing joint replacements. On the one hand, cemented THRs exhibit superior long-term as well as short-term survival [16]. On the other hand, however, whether cemented TKRs yield superior overall survivorship remains uncertain [16]. Likewise, the antimicrobial efficacy of ALBC has not been convincingly demonstrated. Despite strong evidence of high local antibiotic concentrations, both immediately after implantation and sustainably over several months [17-19], its clinical benefit remains controversial: while some meta-analyses report a significantly reduced PPI rate in primary and revision arthroplasty $[20,21]$, others found no effect $[22,23]$. This discrepancy is further aggravated by several key disadvantages, such as the development of antibiotic-resistant bacterial strains [24, $25]$, thermal injury to surrounding tissues [26, 27], economical expenses for hospitals and tax payers [28], and the risk of allergenic potential to surgeons and patients [29-31].

We recently reported on 250 patients who had been referred to our outpatient allergy clinic with a history of complicated cemented arthroplasty and suspected implant allergy [32]. After mechanical problem elicitors, such as loosening or malalignment, had been ruled out by the transferring orthopaedic surgeon by means of clinical and radiographic investigations, extended patch testing with implant metals and the additional $\mathrm{BC}$ series was carried out at our clinic. We found positive reactions in 138 patients (55\%), in particular, $41 / 138$ reactions (30\%) to implant metals and 49/138 (36\%) to BC components. Interestingly, gentamicin sulfate triggered positive readouts in $25 / 250$ patients $(10 \%)$, with $17 / 25$ reactions $(68 \%)$ only appearing as late as day 6 . However, the clinical relevance of positive patch tests to $\mathrm{BC}$ components has merely been suggested in a handful of case reports [33-36], with literature on revisions in the context of gentamicin allergy lacking completely. Thus, we followed up with our patients in an effort to investigate the rate and outcomes of reoperations in this cohort. To this end, our present study is the first to objectify symptom improvement after TJR and ALBC exchange in the context of gentamicin allergy. Our data emphasize both the clinical importance of an adequate work-up in cases of suspected allergic implant failure and the benefit of revisional surgery in cases of confirmed gentamicin allergy.

\section{Methods}

Patient cohort

The present retrospective case series was approved by the local ethics committee (Reference number 159-14). By way of background, for over 20 years, we have been offering outpatient consultations for patients suspected of suffering from adverse implant reactions. Presenting with otherwise unexplained complicated and painful TJRs, dental and osteosynthetic materials, or other implants, such as cardiac pacers, these patients are referred to us by colleagues from a wide variety of fields. According to general consensus, we request that commonplace symptom elicitors be eliminated antecedently. In line with this, extrinsic factors are ruled out, and diagnostic approaches to potential articular etiologies are exhausted prior to consulting with us (Fig. 1). Once symptomatic patients have completed this initial orthopaedic routine work-up with inconclusive results, other systemic symptom elicitors are ruled out before specific allergic testing is commenced (Fig. 2). In order to establish the diagnosis of exclusion of an adverse implant reaction, a three-stage work-up algorithm is then followed: (1) Patch testing is 


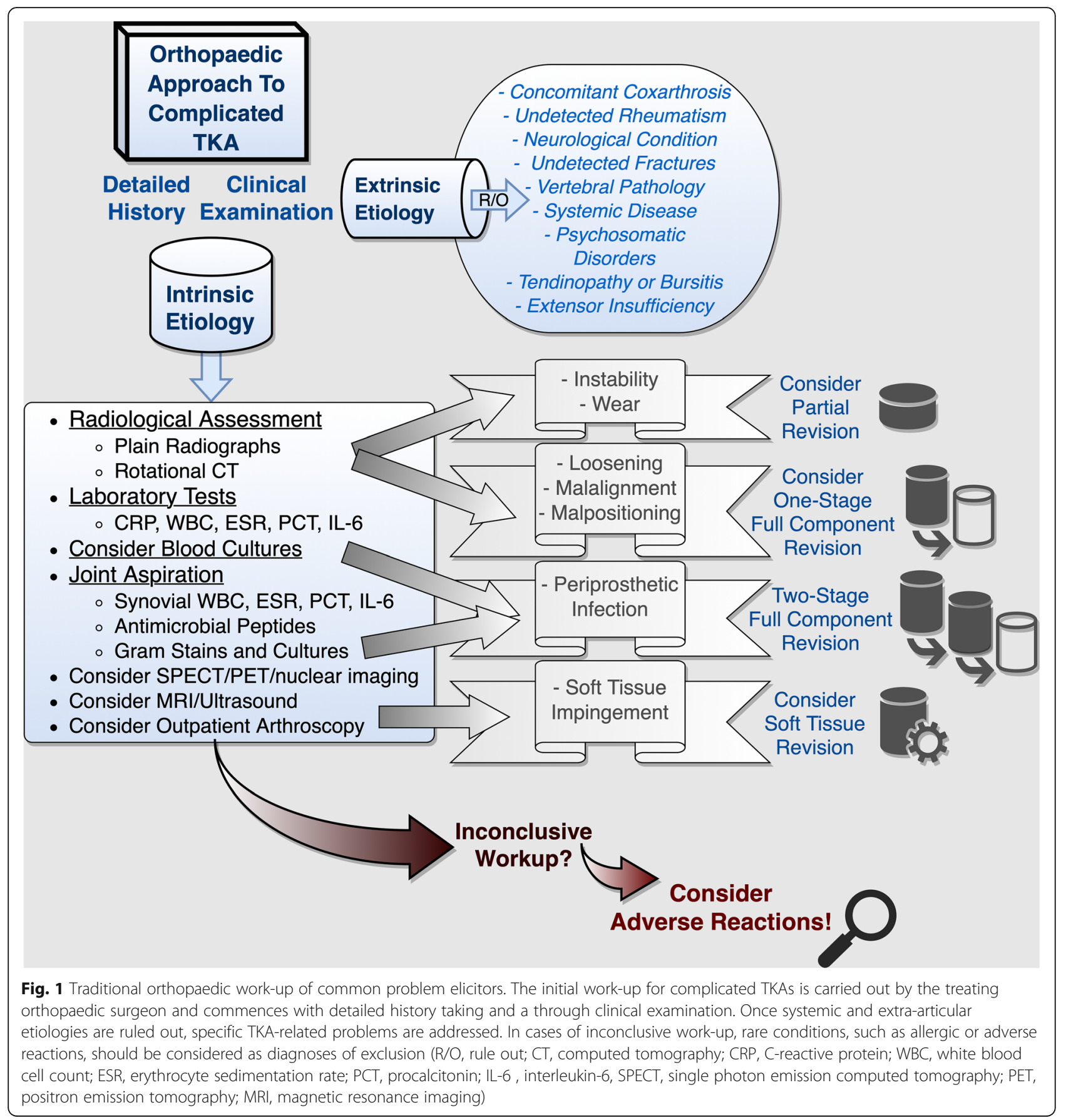

initiated with three sets of substances (common allergens, metallic allergens, and bone cement components, see Tables 1 and 2). This is accompanied by lymphocyte transformation testing in order to check for acquired systematic sensitization as well as histopathological assessment of potential locoregional periprosthetic hypersensitivity.

Amongst the previously tested 250 patients, all TKR bearers with positive patch test reactions to gentamicin were invited to a follow-up appointment at our clinic, as well as clinical and radiographic investigations carried out by the treating orthopaedic surgeons. Initial questionnaireaided history, self-reported and questionnaire-aided anamnesis (including the German version of the Knee Injury and Osteoarthritis Outcome Score [KOOS]) [37, 38], and results from examinations for atopic diathesis were readily available, in addition to the primary clinical and radiographic orthopaedic examinations. An extended European baseline patch test series (Almirall Hermal, Reinbek, Germany), extended metal series (Chemotechnique Diagnostics, Vellinge, Sweden), and BC series had been tested as 


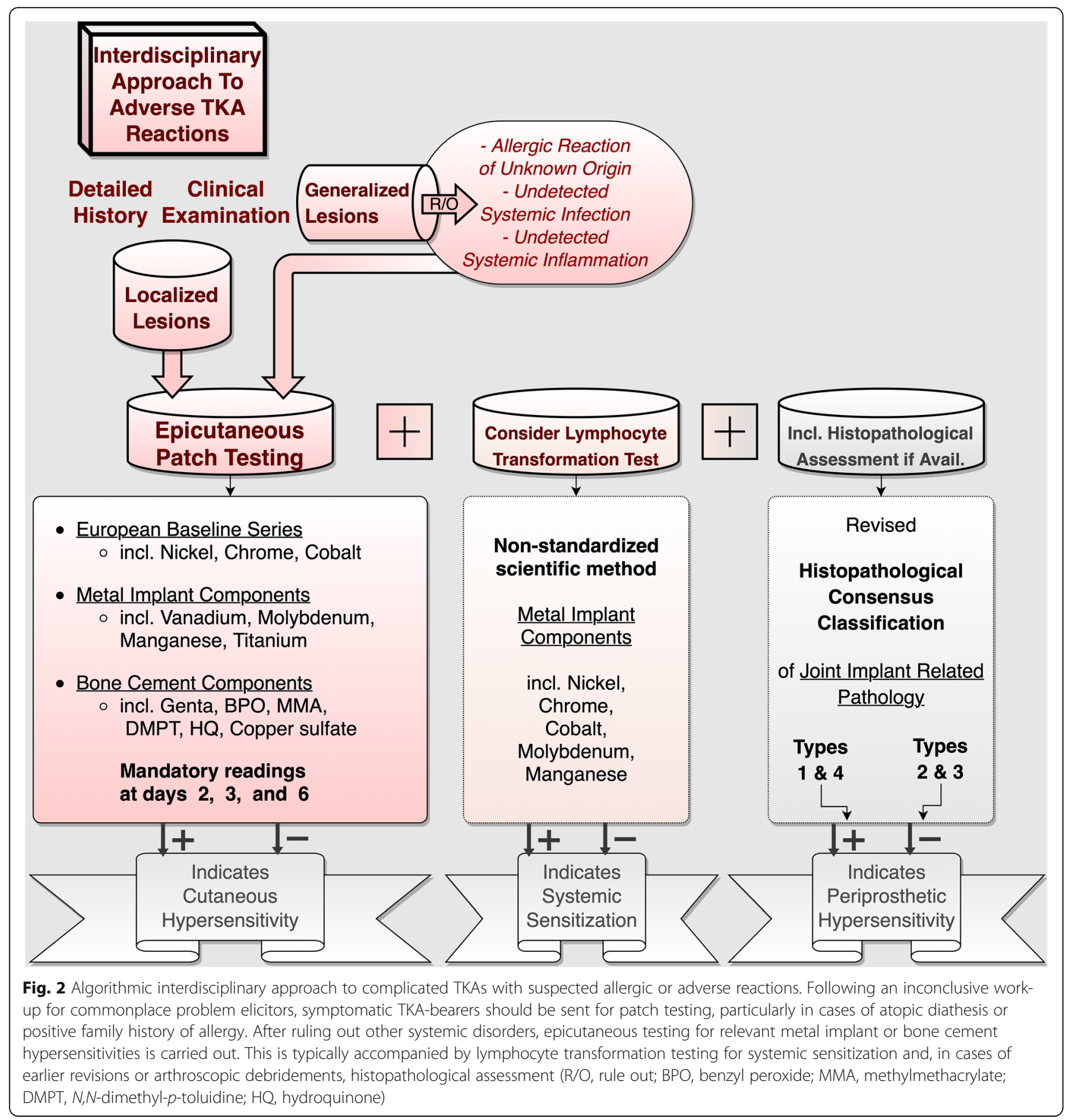

previously described [32], and readouts had likewise been documented in our database. Primary TKR fixation with gentamicin-loaded $\mathrm{BC}$ was reaffirmed by review of the respective operative reports and implant passports.

Figure 3 illustrates the underlying patient inclusion/exclusion criteria for the present follow-up study.

\section{Follow-up procedure}

After obtaining written informed consent, patients were reexamined by the referring orthopaedic surgeon and then re-assessed at our clinic by (i) means of a set of follow-up questions including potential revision surgeries with exchange of implant or $\mathrm{BC}$ components, (ii) recording any history of past and present implant-related complaints and the course of symptoms, and (iii) re-assessment of the KOOS Index. Based on the reported incidence of revision, patients were grouped into an "untreated"(i.e., no revision with exchange of implant or BC components) and a "treated" cohort (i.e., revision with change to an uncemented TKA or re-implantation with gentamicin-free cement). 
Table 1 As part of the European baseline series (EBS) of haptens (contact allergens), 29 substances, prepared at different concentrations (conc.) in either a petrolatum (pet.) or aqueous (aq.) base (veh. = vehicle), are applied to the patient's upper back in the form of a standardized commercially available patch test set

\begin{tabular}{|c|c|c|c|c|}
\hline European baseline series & Allergen & Conc. & Veh. & Readings \\
\hline & Potassium dichromate & $0.5 \%$ & pet. & D2, D3, D6 \\
\hline & Thiuram mix & $1.0 \%$ & pet. & D2, D3, D6 \\
\hline & Cobalt(II) chloride & $1.0 \%$ & pet. & D2, D3, D6 \\
\hline & Myroxylon pereirae & $25 \%$ & pet. & D2, D3, D6 \\
\hline & Colophonium & $20 \%$ & pet. & D2, D3, D6 \\
\hline & $N$-isopropyl- $N^{\prime}$-phenyl-p-phenylenediamine & $0.1 \%$ & pet. & D2, D3, D6 \\
\hline & Lanolin alcohol & $30 \%$ & pet. & D2, D3, D6 \\
\hline & Mercapto mix & $1.0 \%$ & pet. & D2, D3, D6 \\
\hline & Epoxy resin & $1.0 \%$ & pet. & D2, D3, D6 \\
\hline & Nickel(II) sulfate & $5.0 \%$ & pet. & D2, D3, D6 \\
\hline & p-tert-Butylphenol formaldehyde resin & $1.0 \%$ & pet. & D2, D3, D6 \\
\hline & Formaldehyde & $1.0 \%$ & aq. & D2, D3, D6 \\
\hline & Fragrance mix I & $8.0 \%$ & pet. & D2, D3, D6 \\
\hline & Turpentine & $10 \%$ & pet. & D2, D3, D6 \\
\hline & Methylchloroisothiazolinone/methylisothiazolinone & 100 ppm & aq. & D2, D3, D6 \\
\hline & Paraben mix & $16 \%$ & pet. & D2, D3, D6 \\
\hline & Cetearyl alcohol & $20 \%$ & pet. & D2, D3, D6 \\
\hline & Zinc diethyldithiocarbamate & $1.0 \%$ & pet. & D2, D3, D6 \\
\hline & Methyldibromo glutaronitrile & $0.2 \%$ & pet. & D2, D3, D6 \\
\hline & Propolis & $10 \%$ & pet. & D2, D3, D6 \\
\hline & Bufexamac & $5.0 \%$ & pet. & D2, D3, D6 \\
\hline & Compositae mix II & $5.0 \%$ & pet. & D2, D3, D6 \\
\hline & Mercaptobenzothiazole & $2.0 \%$ & pet. & D2, D3, D6 \\
\hline & Hydroxyisohexyl 3-cyclohexene carboxaldehyde & $5.0 \%$ & pet. & D2, D3, D6 \\
\hline & 2-Bromo-2-nitropropane-1,3-diol & $0.5 \%$ & pet. & D2, D3, D6 \\
\hline & Fragrance mix II & $14 \%$ & pet. & D2, D3, D6 \\
\hline & Ylang Ylang $(I+\mid I)$ oil & $10 \%$ & pet. & D2, D3, D6 \\
\hline & Sandalwood oil & $10 \%$ & pet. & D2, D3, D6 \\
\hline & Jasmine absolute & $5.0 \%$ & pet. & D2, D3, D6 \\
\hline
\end{tabular}

\section{Statistics}

Statistical analysis was performed with IBM SPSS Version 20 (IBM Corporation, Armonk, NY, USA) and Graphpad Prism Version 7 (Graphpad Software, Inc., La Jolla, CA, USA). Primary and follow-up KOOS scores were compared using the paired $t$ test to assess the differences in means. To assess the relationship between baseline KOOS scoring and the grouping variable ("treated" versus "untreated"), a one-tailed Pearson correlation coefficient was computed using a linear bivariate regression model. A two-way repeated-measures analysis of variance (ANOVA) was then run to determine whether the independent grouping variable ("treated" versus "untreated") had an effect on KOOS score differences. An error probability of $p \leq 0.05$ was considered statistically significant.

\section{Results}

\section{Patient characteristics}

Twenty-five symptomatic TKR bearers with proven gentamicin hypersensitivity were identified and invited to a follow-up interview, as well as clinical and radiographic investigations, with 15 of 25 allergic patients $(60 \%)$ agreeing to partake in our study. The entire follow-up cohort of these 15 gentamicin allergic patients had initially been treated with cemented TKRs based on cobalt, chromium, and molybdenum (CoCrMo) alloy, which typically include $\sim 65 \%$ cobalt, $\sim 28 \%$ chromium, $\sim 6 \%$ molybdenum, and up to $1 \%$ nickel. The median age was 66 years (49-74 years), and 8 (53\%) patients were female. All 15 patients had initially been referred to our clinic because of persistent and otherwise unexplained 
Table 2 As part of the extended metal and bone cement series, 11 additional substances, each commercially available and prepared at different concentrations (conc.) in either a petrolatum (pet.) or aqueous (aq.) base (veh. = vehicle), are applied to the patient's upper back in an individualized test set

\begin{tabular}{|c|c|c|c|c|}
\hline Metal and bone cement series & Allergen & Conc. & Veh. & Readings \\
\hline & Titanium(IV)-oxide & $0.1 \%$ & pet. & D2, D3, D6 \\
\hline & Manganese(II)-chloride & $0.5 \%$ & pet. & D2, D3, D6 \\
\hline & Molybdenum(V)-chloride & $2.0 \%$ & pet. & D2, D3, D6 \\
\hline & Vanadium-pentoxide & $10 \%$ & pet. & D2, D3, D6 \\
\hline & 2-Hydroxyethylmethacrylate & $1.0 \%$ & pet. & D2, D3, D6 \\
\hline & Copper(II) sulfate & $1.0 \%$ & aq. & D2, D3, D6 \\
\hline & Benzoyl peroxide & $1.0 \%$ & pet. & D2, D3, D6 \\
\hline & Gentamicin sulfate & $20 \%$ & pet. & D2, D3, D6 \\
\hline & Hydroquinone & $1.0 \%$ & pet. & D2, D3, D6 \\
\hline & $N, N$-Dimethyl-p-toluidine & $2.0 \%$ & pet. & D2, D3, D6 \\
\hline & Methylmethacrylate & $2.0 \%$ & pet. & D2, D3, D6 \\
\hline
\end{tabular}

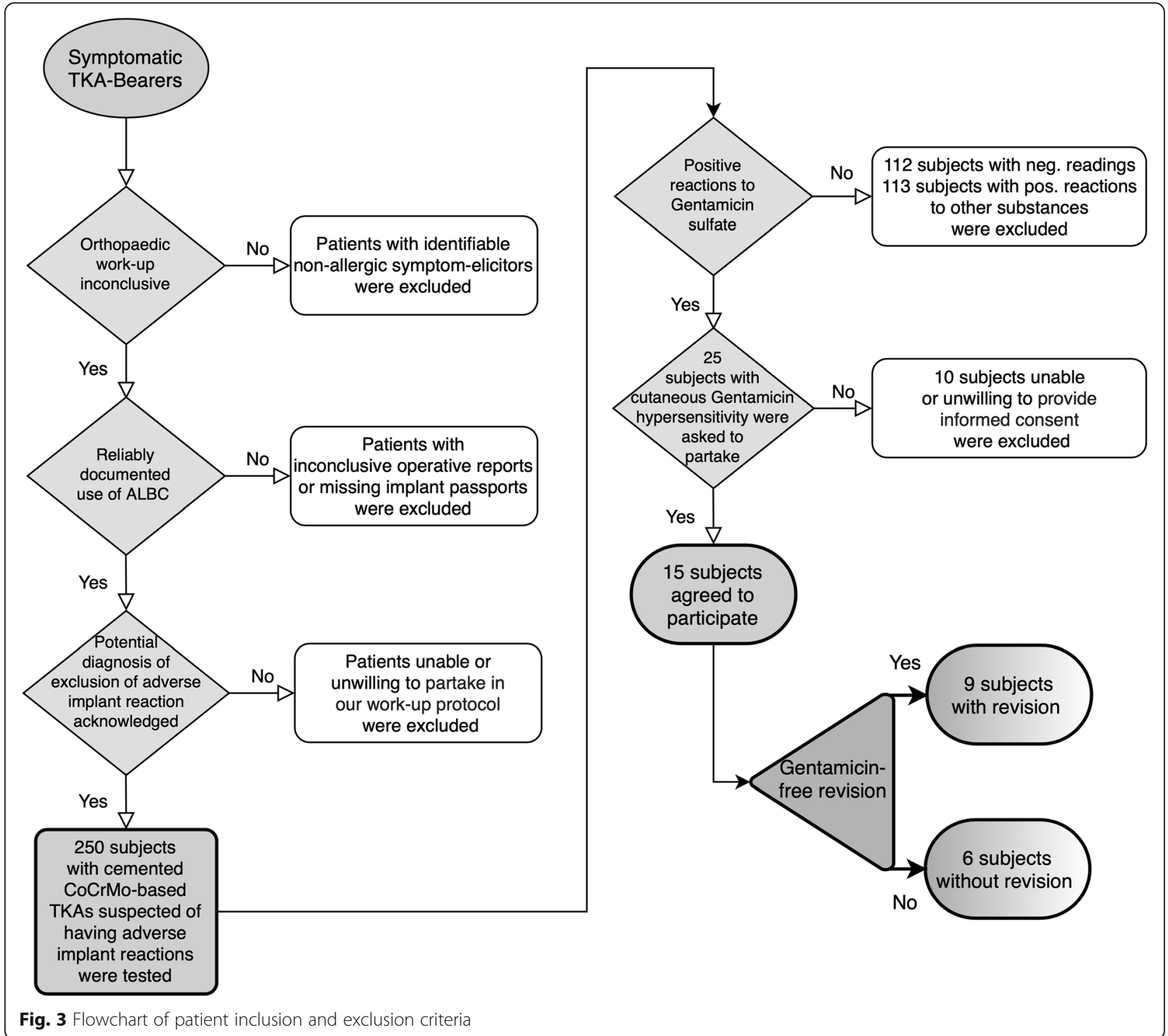


symptoms related to their TKR, after commonplace failure modes, such as bacterial infection, aseptic loosening, or malalignment had been excluded by the transferring orthopaedic surgeon prior to consultation with us. The mean implant to allergy work-up interval amounted to 18 months (4-53 months). At first visit, 12 patients complained of joint pain and limited mobility, respectively, 11 reported a history of recurrent swellings, and 7 noted intermittent joint effusions. Eczema $(n=3)$ and erythema $(n=1)$ were seldom stated (multiple complaints were reported per individual patient). Four patients had noticed previous adverse reactions (e.g., pruritus, erythema, and eczema) upon contact with metallic objects, such as wristwatches or jewelry. Furthermore, 6 patients reported a family history of atopic diathesis. None recalled "intolerance" reactions to topical drugs (including potential gentamicin-containing ointments, such as ear or eye drops). All patients had been found to be patch test positive-i.e., allergic - to gentamicin, with one patient reacting to both gentamicin and BPO. Moreover, two patients had combined reactions to gentamicin sulfate and nickel (II) sulfate. As part of our follow-study, re-assessment including repeated KOOS scoring was carried out after a mean follow-up period of 38 months (23-56 months). Figure 4 illustrates the chronological sequence of the aforementioned time intervals. In addition, a detailed summary of patient characteristics is given in Table 3.

\section{Decision to proceed with revision surgery}

Overall, there was a significant difference between primary and follow-up KOOS scores for the entirety of all 15 patients $(t=3.258, p=0.006, n=15,95 \%$ CI 7.124, 34.53), namely, less severe symptoms were reported at the time of our follow-up interview $(M=62.59$, SD $=$ 14.42) compared to the primary scoring ( $M=41.73$, SD $=20.19$ ). A total of 9 patients had undergone revision surgeries with both the exchange of the TKR and removal of the gentamicin-loaded $\mathrm{BC}$, corresponding to a "treatment" rate of $60 \%$. Mean implant durability before revision was 22 months (15-38 months). Revision surgery was carried out after a mean interval of 4 months
(2-7 months) following our diagnosis of gentamicin contact allergy. For all revisions, change to an uncemented TKA or re-implantation with gentamicin-free cement was confirmed by the operative report and implant passport. There was a significant negative correlation between baseline KOOS scores and the decision to proceed with surgery $(r=-0.442, n=15, p=0.050)$. By way of explanation, high degree of symptom severity (reflected by low KOOS scores) led to an increased probability of revision surgery. A scatterplot visualizes this relationship (Fig. 5). No unequivocal pathologic clinical (i.e., limited range of motion) or radiographic (i.e., malalignment or loosening) findings prompted any of the revision surgeries. In fact, our work-up results were indicated as the decisive criterion in favor of re-operation in all cases.

\section{Beneficial effect of gentamicin-free revision}

Since we were not only interested in the motivation to proceed with revision, but also in the efficacy of these procedures, a repeated measures factorial ANOVA with "treatment status" as an independent binary factor and KOOS scoring as a repeated within-subjects factor was run. This analysis demonstrated a significant effect of the grouping variable ("treated" versus "untreated") in the assumed direction $(F(1,13)=5.877, p=0.031)$, with significantly higher symptom relief after revision surgery (Figure 6). Further subgroup analysis using the paired ttest confirmed this significant improvement in the 'treatment' group ( $\mathrm{t}=2.627, \mathrm{p}=0.028, \mathrm{n}=9,95 \% \mathrm{CI}: 3.289$, 44.73). In contrast, there was no significant change in KOOS scores for patients without revision $(\mathrm{t}=1.748, \mathrm{p}$ $=0.14, \mathrm{n}=6,95 \% \mathrm{CI}:-7.555,39.65)$. Remarkably, one patient of the revision group, however, displayed a score deterioration of 14.4 points (highlighted in dark red in Fig. 6). Upon further investigation, the patient's treating orthopaedic surgeon disclosed his diagnosis of severe intra-articular arthrofibrosis. This multi-faceted complication of TKR is characterized by excessive scar formation, low responsiveness to surgery, and poor functional and symptomatic outcomes [39].

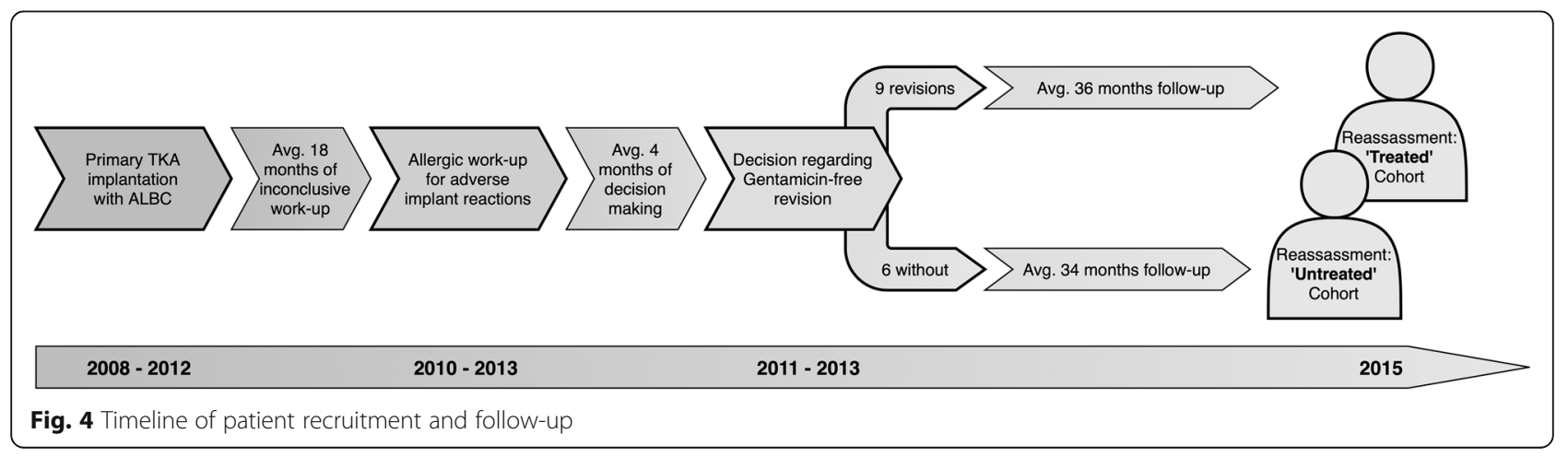


Table 3 Patient and implant characteristics including date of implantation and implant type, allergy history, symptoms, patch test results, timing of allergy work-up and revision surgery, and change in KOOS scores (CoCroMo incl. Ni+, cobalt-chromiummolybdenum alloy includes up to 1\% nickel; AA, allergic asthma; AR, allergic rhinitis; FA, family history of atopy; $A E$, atopic eczema; ARM, self-reported intolerance reactions to metallic objects; JP, joint pain; Sw, swelling; Er, localized erythema; Ec, localized eczema; JE, joint effusion; LA, limited ambulation; Genta, gentamicin; Ni, nickel; BPO, benzoyl peroxide)

\begin{tabular}{|c|c|c|c|c|c|c|c|c|c|c|}
\hline$\overline{\mathrm{ID}}$ & Implantation & $\begin{array}{l}\text { Manufacturer: } \\
\text { model }\end{array}$ & Alloy & $\begin{array}{l}\text { Allergy } \\
\text { history }\end{array}$ & Symptoms & $\begin{array}{l}\text { Patch } \\
\text { test }\end{array}$ & $\begin{array}{l}\mathrm{JR} \rightarrow \mathrm{WU} \\
+\end{array}$ & $\begin{array}{l}\mathrm{JR} \rightarrow \mathrm{RS} \\
\S\end{array}$ & $\begin{array}{l}\mathrm{WU} \rightarrow \mathrm{FU} \\
\mathrm{E}\end{array}$ & $\begin{array}{l}\text { KOOS } \\
\text { Diff } \neq\end{array}$ \\
\hline 1 & Apr 04, 2008 & $\begin{array}{l}\text { Zimmer: } \\
\text { Protasul }\end{array}$ & $\begin{array}{l}\text { CoCroMo } \\
\text { (incl. } \mathrm{Ni+} \text { ) }\end{array}$ & none & $J P, S W, J E, L A$ & Genta & 28 & 33 & 56 & +62.1 \\
\hline 2 & Apr 09, 2009 & $\begin{array}{l}\text { DePuy: } \\
\text { LCS }\end{array}$ & $\begin{array}{l}\text { CoCroMo } \\
\text { (incl. } \mathrm{Ni+} \text { ) }\end{array}$ & FA & $J P, L A$ & Genta & 19 & 22 & 54 & +18.9 \\
\hline 3 & Apr 22, 2010 & $\begin{array}{l}\text { Smith and Nephew: } \\
\text { Genesis II }\end{array}$ & $\begin{array}{l}\text { CoCroMo } \\
\text { (incl. } \mathrm{Ni+} \text { ) }\end{array}$ & FA & $J P, S W, J E, L A$ & Genta & 11 & 15 & 52 & +07.6 \\
\hline 4 & Jul 02, 2010 & $\begin{array}{l}\text { DePuy: } \\
\text { PFC }\end{array}$ & $\begin{array}{l}\text { CoCroMo } \\
\text { (incl. } \mathrm{Ni}+\text { ) }\end{array}$ & FA & $J P, S W, J E, L A$ & Genta & 13 & 17 & 45 & +68.9 \\
\hline 5 & Apr 12, 2011 & $\begin{array}{l}\text { DePuy: } \\
\text { PFC }\end{array}$ & $\begin{array}{l}\text { CoCroMo } \\
\text { (incl. } \mathrm{Ni+} \text { ) }\end{array}$ & AR, ARM & $J P, S W, E r, E c, L A$ & Genta & 4 & no rev & 45 & +11.3 \\
\hline 6 & Mar 28, 2010 & $\begin{array}{l}\text { Biomet Oxford: } \\
\text { Vanguard }\end{array}$ & $\begin{array}{l}\text { CoCroMo } \\
\text { (incl. } \mathrm{Ni+} \text { ) }\end{array}$ & $A R, A A, A E$ & SW, JE & Genta & 19 & no rev & 43 & -04.6 \\
\hline 7 & $\operatorname{Jan} 21,2011$ & $\begin{array}{l}\text { Zimmer: } \\
\text { INNEX }\end{array}$ & $\begin{array}{l}\text { CoCroMo } \\
\text { (incl. } \mathrm{Ni+} \text { ) }\end{array}$ & none & $J P, S W, L A$ & Genta & 14 & 18 & 37 & +33.4 \\
\hline 8 & Feb 28, 2011 & $\begin{array}{l}\text { DePuy: } \\
\text { PFC }\end{array}$ & $\begin{array}{l}\text { CoCroMo } \\
\text { (incl. Ni+) }\end{array}$ & none & $J P, S W$ & Genta & 13 & 17 & 37 & +19.2 \\
\hline 9 & Feb 18, 2011 & $\begin{array}{l}\text { DePuy: } \\
\text { PFC }\end{array}$ & $\begin{array}{l}\text { CoCroMo } \\
\text { (incl. Ni+) }\end{array}$ & none & SW, LA & Genta & 16 & no rev & 35 & +01.5 \\
\hline 10 & Aug 06, 2009 & $\begin{array}{l}\text { Endoplant: } \\
\text { Solution EPP }\end{array}$ & $\begin{array}{l}\text { CoCroMo } \\
\text { (incl. } \mathrm{Ni+} \text { ) }\end{array}$ & $A R, A A, A E, F A$ & $J P, S W, L A$ & Genta & 35 & 38 & 33 & -14.4 \\
\hline 11 & Sep 16, 2011 & $\begin{array}{l}\text { DePuy: } \\
\text { PFC }\end{array}$ & $\begin{array}{l}\text { CoCroMo } \\
\text { (incl. } \mathrm{Ni+} \text { ) }\end{array}$ & none & $J P, E C, J E, L A$ & Genta, BPO & 13 & no rev & 31 & +03.8 \\
\hline 12 & Sep 09, 2008 & $\begin{array}{l}\text { DePuy: } \\
\text { LCS }\end{array}$ & $\begin{array}{l}\text { CoCroMo } \\
\text { (incl. } \mathrm{Ni+} \text { ) }\end{array}$ & $A R, A R M, F A$ & $J P, S W, L A$ & Ni, Genta & 53 & no rev & 26 & +56.0 \\
\hline 13 & Aug 20, 2012 & $\begin{array}{l}\text { Stryker: } \\
\text { Triathlon }\end{array}$ & $\begin{array}{l}\text { CoCroMo } \\
\text { (incl. } \mathrm{Ni+} \text { ) }\end{array}$ & ARM & $J P, E C, J E, L A$ & Genta & 6 & no rev & 26 & +28.8 \\
\hline 14 & Aug 26, 2011 & $\begin{array}{l}\text { Zimmer: } \\
\text { INNEX }\end{array}$ & $\begin{array}{l}\text { CoCroMo } \\
\text { (incl. } \mathrm{Ni+} \text { ) }\end{array}$ & FA & $J P, S W, J E, L A$ & Genta & 19 & 27 & 25 & +03.7 \\
\hline 15 & Jun 06, 2012 & $\begin{array}{l}\text { Zimmer: } \\
\text { Nexgen }\end{array}$ & $\begin{array}{l}\text { CoCroMo } \\
\text { (incl. } \mathrm{Ni}+\text { ) }\end{array}$ & ARM & $J P, S W, J E, L A$ & Ni, Genta & 12 & 15 & 23 & +16.7 \\
\hline
\end{tabular}

tInterval between primary implantation of joint replacement (JR) and allergy work-up (WU) in months SInterval between primary implantation of joint replacement (JR) and revision surgery (RS) in months flnterval between allergy work-up (WU) and follow-up (FU) in months ‡Individual KOOS index difference (absolute change)

\section{Discussion}

Our follow-up investigation revealed that severely impaired TKA patients were more likely to not only acknowledge previously detected gentamicin allergy, but also to undergo revision surgery. Postoperative re-evaluation showed a significant improvement in KOOS scores in these patients-i.e., they benefited greatly from revision surgery. Since none of the traditional symptom elicitors had previously been detected (such as PPI or malalignment), allergy work-up was not only simply requested, but proven gentamicin allergy was in fact regarded as indication for revision surgery by the treating surgeons. This underlines the importance of a thorough allergy work-up in cases of otherwise unexplained TJR symptoms.
Indeed, up to $20 \%$ of TKA bearers remain dissatisfied and complain of persisting symptoms, such as joint stiffness, loss of range of motion, knee pain, and recurrent swelling or edema, following TKR [40, 41]. Despite a certain disagreement regarding the definition of arthroplasty failure in this context, almost a quarter of all TKA bearers undergoes surgical revision, mostly for aseptic loosening or PPI [42]. However, increasing numbers of revisions for unclear symptoms or following inconclusive work-up procedures are being recorded annually [43, 44]. It is in the context of these cases, that the present study is intending to raise awareness for rare problem elicitors, such as allergic or adverse reactions. As a matter of fact, only about $10 \%$ of orthopaedic surgeons report that they regularly screen their patients for relevant hypersensitivities [45]. 


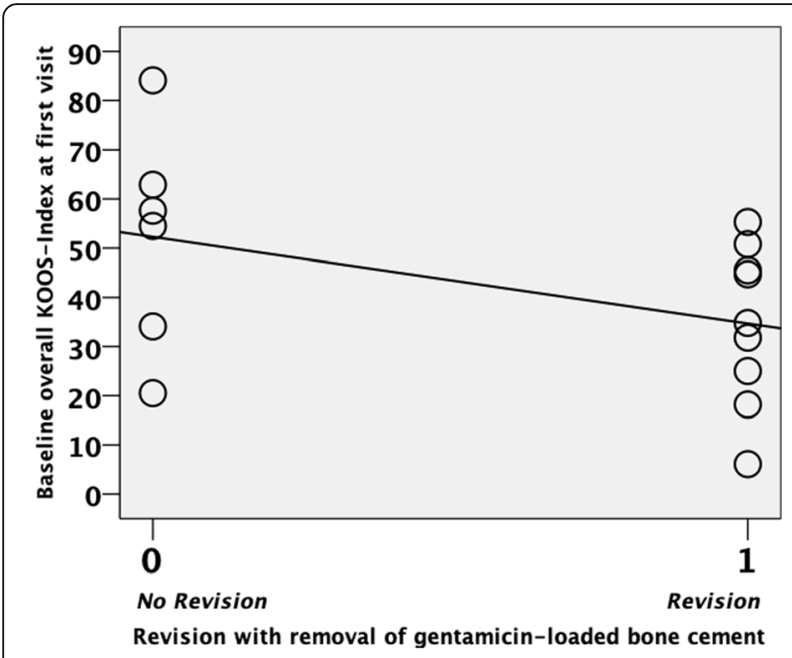

Fig. 5 Correlation of KOOS scores upon first visit and the incidence of revision surgery. Baseline KOOS (Knee Injury and Osteoarthritis Outcome Score) indices of the 15 patients at first visit (i.e., time of allergy diagnostics). Scatterplot displaying the correlation of low KOOS indices (i.e., high symptom severity) and the decision to proceed with revision surgery in 9 patients ("revision")

Clinical observations of $\mathrm{BC}$ allergy as potential elicitor of arthroplasty failure have been reported as early as the 1970s [46, 47]: the allergens in question were acrylates, namely, methylmethacrylate (MMA) and additives, like BPO or DMPT. In 1996, Haddad et al. observed a high prevalence of positive patch test reactions to DMPT in a series of patients with early onset of aseptic implant

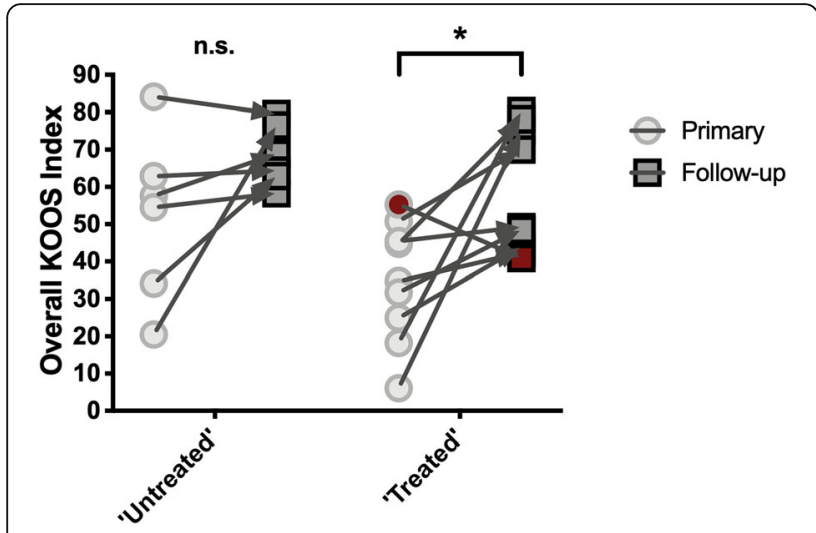

Fig. 6 Revision surgery provides significant symptom relief in allergic patients. Split-plot repeated measures factorial ANOVA visualizing the improvement of KOOS (Knee Injury and Osteoarthritis Outcome Score) indices in the 6 patients without revision ("untreated") and the 9 patients with revision ("treated"). Improvement was significant only in the "treated" group. Of note, patient 10 of the revision group displayed a score deterioration of 14.4 points (dark red). In this case, severe intra-articular arthrofibrosis was confirmed as the symptom elicitor by the treating orthopaedic surgeon. n.s., not statistically significant; ${ }^{*} p<0.05$, primary, at first visit (i.e., time of allergy diagnostics) loosening [48]. The importance of adequate preoperative history taking and patch testing-e.g., in patients with contact dermatitis to acrylic finger nails-has been discussed in a 2002 case report by Kaplan et al. [49] and a recent report by Alamri and colleagues [50]. Despite several reports focusing on BPO as an allergenic component in poorly tolerated cemented TJRs, its role in implant allergy remains controversial [51, 52]; BPO, despite its strong irritant potential, only acts as a weak allergen, resulting in false positive patch test reactions [53, 54]. Furthermore, its ongoing release from bone cement is questionable. This doubt is supported by the fact that BPO is metabolized rapidly as part of its function as redox initiator in the polymerization process $[8,9]$. It is therefore doubtful whether BPO remnants are still present at the site of cementation after the curing process is complete. Nonetheless, Bircher et al. showed that removal of $\mathrm{BC}$ and change to uncemented endoprostheses resulted in considerable symptomatic improvements in 4 out of $5 \mathrm{BPO}$ allergic patients with TJR [34]. Similarly, Vega et al. [36] and Kenan et al. [35] observed satisfactory long-term courses of uncemented revision arthroplasties in patients allergic to MMA, a BC component known to remain considerably longer at the site of implantation in cases of incomplete polymerization.

In our patients, however, the main reason for revision surgery was contact allergy to gentamicin sulfate, as confirmed by positive patch testing. Aminoglycoside antibiotics are well studied contact allergens [55], known to be responsible for contact dermatitis to topical drugs in particular, with gentamicin sulfate leading the way [56]. In line with this, a longitudinal study of 620 Finnish patients with suspected contact allergy revealed a $4.6 \%$ prevalence of positive patch test reactions to gentamicin [57]. However, our 15 patients did not report any intolerance or dermatitis to topical (potentially gentamicin containing) drugs. On the other hand, due to lifetime cumulative exposure, contact allergy to topical drugs becomes more prevalent with advancing age, which coincides with an increased demand for TJR [58]. However, reports of gentamicin allergy in cemented arthroplasty are scarce, apart from our preceding study [32]. Haeberle et al. presented a patient with a potentially gentamicin-related systemic contact dermatitis upon cemented TKR [59]. Christiansen et al. even reported a case of anaphylaxis with cardiac arrest after intravenous administration of gentamicin during a routine laparoscopic procedure, with thorough work-up revealing a previous cemented TKR as the suspected cause of sensitization [60]. Albeit devastating, the patient's symptoms were of systemic nature and did not affect the TJR itself.

The abovementioned acute systemic reactions are starkly contrasted by the late onset and prolonged 
persistence of localized symptoms in our cohort of contact allergic patients. Allergic reactions in the sense of delayed type hypersensitivity may persist for a longer period of time even when continuous allergen exposure is low or has already stopped. This fact was well illustrated in an exemplary case by Wittman et al. [61], who described a gentamicin allergic patient with persistent and otherwise unexplained local symptoms following uncemented TKR. Meticulous history taking revealed a single intra-articular injection of gentamicin performed during an outpatient check-up as the elicitor of monthslong local pain and swelling in this case. Of note, our results also demonstrate that in patients with less pronounced symptoms, complaints decreased as well, but they did so to a lesser degree. This might be explained by the gradually decreasing gentamicin release from $\mathrm{BC}$ over time.

Finally, our present study does have some weaknesses. First, and most importantly, our cohort only comprised a relatively small number of individuals, which complicates the generalizability of the conclusions drawn. Nevertheless, taking the large sample size of the primary study population into account, the numbers are sufficiently high to emphasize the importance of gentamicin contact allergy in complicated TJR. Secondly, our study is limited by its retrospective nature and involvement of several treating orthopaedic surgeons and their presumably slightly different treatment protocols, particularly with regard to their preference of considering positive patch test reactions as an indication for revision surgery. Third, we did not include serological investigations, histopathological sampling, or molecular methods to aid in the diagnosis of hypersensitivity. Thus, we were not able to compare the aforementioned diagnostic techniques in the context of suspected allergy to bone cement components. However, patch testing still remains the gold standard in detecting symptomatic contact allergy and was therefore deemed sufficient as the sole diagnostic criterion. Fourth, we did not analyze further patient characteristics, such as the pre-arthroplasty condition of their knees, potentially confounding comorbidities, or socioeconomic status, all of which might have contributed to their unsatisfactory primary TKA outcomes. Fifth, only 15 of all 25 patients diagnosed with gentamicin contact allergy were available for a follow-up visit, which might represent an inherent selection bias: namely, patients diagnosed with gentamicin contact allergy who did not profit from revision surgery might have refused to participate in our follow-up study, as opposed to those who did. Ultimately, we only used the KOOS to evaluate the course of symptoms and assess post-revision outcomes. Despite good evidence for reliability, validity, and responsiveness, the KOOS remains a solely self-reported score, omitting further objectifiable clinical and diagnostic criteria (such as range of motion or radiographic measurements) [62,63]. One could therefore argue that an alternative scoring system, such as the New Knee Society Score, which contains a section of objective findings, would be better suited to determine the potential benefit of TKA revisions [64, 65]. However, despite these acknowledged weaknesses, our study provides encouraging evidence for the clinical relevance of an allergy work-up in cases of complicated TJR. These limitations do not weaken the strong correlation between gentamicin contact allergy and symptom improvement following revision surgery.

\section{Conclusion}

With an ever-aging population, the demand of TJR is on the rise. At large, arthroplasty failure results in both a far-reaching physical and considerable financial burden on patients, physicians, and taxpayers. Consequently, trying to elucidate the mechanisms of premature implant failure remains a crucial multi-disciplinary challenge. In this context, particularly when symptoms persist despite an inconclusive work-up, rare conditions like implant allergy or adverse reactions should be considered as diagnoses of exclusion. In conclusion, our findings indicate that gentamicin allergy could represent a relevant problem elicitor in cemented arthroplasty. To our knowledge, this is the first study assessing the clinical relevance of gentamicin contact allergy in a single-center cohort of symptomatic patients with aseptic cemented TKR. To conclude, larger cohort studies, preferably multicenter in nature, as well as investigations of other joints, need to be performed to further corroborate our findings regarding the clinical relevance of gentamicin allergy in TKA.

\section{Abbreviations}

ALBC: Antibiotic-loaded bone cement; ANOVA: Analysis of variance; BC: Bone cement; BPO: Benzyl peroxide; CoCrMo: Cobalt, chromium, and molybdenum; DMPT: N,N-Dimethyl-p-toluidine; e.g.: For example; i.e.: That is; KOOS: Knee Injury and Osteoarthritis Outcome Score; M : Mean/average; MMA: Methylmethacrylate; PMMA: Poly-methylmethacrylate;

PPI: Periprosthetic infection; SD: Standard deviation; THR: Total hip replacement; TJA: Total joint arthroplasty; TJR: Total joint replacement; TKR: Total knee replacement

\section{Acknowledgements}

We gratefully acknowledge the expert technical assistance of Ralf Pohl.

\section{Authors' contributions}

BT participated in the design and the conception of the study, carried out data acquisition, performed the statistical analysis and interpretation of data, and drafted the manuscript. MB participated in data acquisition. AA, FK, and

$\mathrm{RB}$ participated in data interpretation and manuscript revision. BS participated in study design, data acquisition, statistical analysis and interpretation of data, and manuscript revision. PT and EO participated in the conception of the study and the interpretation of data and were major contributors in writing and revising the manuscript. All authors read and approved the final manuscript.

\section{Funding}

This work was supported by the non-profit organization "German Osteoarthritis Society" ("Deutsche Arthrose-Hilfe e.V."). 


\section{Availability of data and materials}

The datasets used and analyzed during the current study are available from the corresponding author on reasonable request.

\section{Ethics approval and consent to participate}

This study has been performed in accordance with the ethical standards in the 1964 Declaration of Helsinki. Ethical approval for this study was obtained from the local ethics committee "Ethikkommission bei der LMU München" (Munich, Germany, Reference No. 159-14). Written informed consent was obtained from all patients for their anonymized information to be published in this article.

\section{Consent for publication}

Not applicable.

\section{Competing interests}

The institution of $B T, M B, A A, F K, B S, P T$, and $E O$ has received funding from the non-profit "German Osteoarthritis Society" ("Deutsche Arthrose-Hilfe e.V.") to support this clinical study. All authors confirm that this funding source had no involvement regarding in study design; in the collection, analysis, and interpretation of data; in the writing of the report; and in the decision to submit the article for publication. Each author certifies that he or she has no commercial associations (e.g., consultancies, stock ownership, equity interest, and patent/licensing arrangements) that might pose a conflict of interest in connection with the submitted article.

\section{Author details}

'Department of Dermatology and Allergology, Ludwig-Maximilians-University Munich, Frauenlobstrasse 9-11, 80337 Munich, Germany. ${ }^{2}$ Department of Hand, Plastic, and Reconstructive Surgery, Burn Center, BG Trauma Center, University of Heidelberg, Ludwig-Guttmann-Strasse 13, 67071 Ludwigshafen, Germany. ${ }^{3}$ Department of Anesthesiology and Intensive Care, Technical University of Munich, Ismaninger Strasse 22, 81675 Munich, Germany. ${ }^{4}$ Department of Orthopaedics, University of Rostock, Doberaner Strasse 142, 18057 Rostock, Germany.

Received: 2 February 2020 Accepted: 31 July 2020

Published online: 12 August 2020

\section{References}

1. Department of Research \& Scientific Affairs. Annual incidence of common musculoskeletal procedures and treatment. Am Acad Orthop Surg 2014:15. https://www.aaos.org/CustomTemplates/Content.aspx?id=6407\&ssopc=1 (accessed February 1, 2019).

2. Kurtz S. Projections of primary and revision hip and knee arthroplasty in the United States from 2005 to 2030. J Bone Jt Surg. 2007;89:780. https://doi. org/10.2106/JBJS.F.00222.

3. Wengler A, Nimptsch U, Mansky T. Hip and knee replacement in Germany and the USA. Dtsch Arztebl Int. 2014;111:407-16. https://doi.org/10.3238/ arztebl.2014.0407.

4. Bozic KJ, Kurtz SM, Lau E, Ong K, Chiu V, Vail TP, et al. The epidemiology of revision total knee arthroplasty in the United States. Clin Orthop Relat Res. 2010;468:45-51. https://doi.org/10.1007/s11999-009-0945-0

5. Bozic K, Kurtz SM, Lau E, Ong K, Vail TP, Berry DJ. The epidemiology of revision total hip arthroplasty in the United States. J Bone Jt Surg Am Vol. 2009;91:128-33. https://doi.org/10.2106/JBJS.H.00155.

6. Hebert CK, Williams RE, Levy RS, Barrack RL. Cost of treating an infected total knee replacement. Clin Orthop Relat Res. 1996;331:140-5. https://doi. org/10.1097/00003086-199610000-00019.

7. Kurtz SM, Lau E, Watson H, Schmier JK, Parvizi J. Economic burden of periprosthetic joint infection in the United States. J Arthroplast. 2012;27:6165.e1. https://doi.org/10.1016/..arth.2012.02.022.

8. Breusch SJ, Kühn K-D. Bone cements based on polymethylmethacrylate. Orthopade. 2003:32:41-50. https://doi.org/10.1007/s00132-002-0411-0.

9. Webb JCJ, Spencer RF. The role of polymethylmethacrylate bone cement in modern orthopaedic surgery. J Bone Joint Surg (Br). 2007;89-B:851-7. https://doi.org/10.1302/0301-620X.89B7.19148.

10. Malik M, Gambhir A, Bale L, Pradhan N, Porter M. Primary total hip replacement: a comparison of a nationally agreed quide to best practice and current surgical technique as determined by the North West Regional
Arthroplasty Register. Ann R Coll Surg Engl. 2004. https://doi.org/10.1308/ 003588404322827509

11. Malik M, Chougle A, Pradhan N, Gambhir A, Porter M. Primary total knee replacement: a comparison of a nationally agreed guide to best practice and current surgical technique as determined by the North West Regional Arthroplasty Register. Ann R Coll Surg Engl. 2005;87:117-22. https://doi.org/ 10.1308/1478708051676

12. Robertsson $\mathrm{O}$, Ranstam J, Sundberg M, W-Dahl A, Lidgren L. The Swedish Knee Arthroplasty Register. Bone Jt Res. 2014;3:217-22. https://doi.org/10. 1302/2046-3758.37.2000289.

13. Randelli P, Evola FR, Cabitza P, Polli L, Denti M, Vaienti L. Prophylactic use of antibiotic-loaded bone cement in primary total knee replacement. Knee Surg Sport Traumatol Arthrosc. 2010;18:181-6. https://doi.org/10.1007/ s00167-009-0921-y.

14. Parvizi J, Della Valle CJ. AAOS clinical practice guideline: diagnosis and treatment of periprosthetic joint infections of the hip and knee. Am Acad Orthop Surg. 2010;18:771-2. https://doi.org/10.5435/00124635-20101200000007.

15. Kurtz SM, Ong KL, Lau E, Bozic KJ, Berry D, Parvizi J. Prosthetic joint infection risk after TKA in the medicare population. Clin Orthop Relat Res. 2010;468: 52-6. https://doi.org/10.1007/s11999-009-1013-5.

16. Saleh KJ, El Othmani MM, Tzeng TH, Mihalko WM, Chambers MC, Grupp TM. Acrylic bone cement in total joint arthroplasty: a review. J Orthop Res. 2016; 34:737-44. https://doi.org/10.1002/jor.23184.

17. Stevens CM, Tetsworth KD, Calhoun JH, Mader JT. An articulated antibiotic spacer used for infected total knee arthroplasty: a comparative in vitro elution study of Simplex $x^{\oplus}$ and Palacos ${ }^{\circledR}$ bone cements. J Orthop Res. 2005; 23:27-33. https://doi.org/10.1016/j.orthres.2004.03.003.

18. Anagnostakos K, Kelm J. Enhancement of antibiotic elution from acrylic bone cement. J Biomed Mater Res Part B Appl Biomater. 2009;90B:467-75. https://doi.org/10.1002/jbm.b.31281.

19. Qadir R, Sidhu S, Ochsner JL, Meyer MS, Chimento GF. Risk stratified usage of antibiotic-loaded bone cement for primary total knee arthroplasty: short term infection outcomes with a standardized cement protocol. J Arthroplast. 2014;29:1622-4. https://doi.org/10.1016/j.arth.2014.02.032.

20. Parvizi J, Saleh KJ, Ragland PS, Pour AE, Mont MA. Efficacy of antibioticimpregnated cement in total hip replacement. Acta Orthop. 2008;79:335-41. https://doi.org/10.1080/17453670710015229.

21. Wang J, Zhu C, Cheng T, Peng X, Zhang W, Qin H, et al. A systematic review and meta-analysis of antibiotic-impregnated bone cement use in primary total hip or knee arthroplasty. PLoS One. 2013;8:e82745. https://doi.org/10. 1371/journal.pone.0082745.

22. Schiavone Panni A, Corona K, Giulianelli M, Mazzitelli G, Del Regno C, Vasso M. Antibiotic-loaded bone cement reduces risk of infections in primary total knee arthroplasty? A systematic review. Knee Surg Sport Traumatol Arthrosc. 2016;24:3168-74. https://doi.org/10.1007/s00167-016-4301-0.

23. King JD, Hamilton DH, Jacobs CA, Duncan ST. The hidden cost of commercial antibiotic-loaded bone cement: a systematic review of clinical results and cost implications following total knee arthroplasty. J Arthroplast. 2018:33:3789-92. https://doi.org/10.1016/j.arth.2018.08.009.

24. Arciola CR, Campoccia D, Montanaro L. Effects on antibiotic resistance of Staphylococcus epidermidis following adhesion to polymethylmethacrylate and to silicone surfaces. Biomaterials. 2002;23:1495-502. https://doi.org/10. 1016/50142-9612(01)00275-7.

25. Thomes B, Murray P, Bouchier-Hayes D. Development of resistant strains of Staphylococcus epidermidis on gentamicin-loaded bone cement in vivo. J Bone Joint Surg (Br). 2002. https://doi.org/10.1302/0301-620X.84B5.11907.

26. DiPisa JA, Sih GS, Berman AT. The temperature problem at the bone-acrylic cement interface of the total hip replacement. Clin Orthop Relat Res. 1976: 95-8. https://doi.org/10.1097/00003086-197611000-00013.

27. Mjöberg B, Pettersson $H$, Rosenqvist $R$, Rydholm A. Bone cement, thermal injury and the radiolucent zone. Acta Orthop Scand. 1984;55:597-600. https://doi.org/10.3109/17453678408992403.

28. Gutowski CJ, Zmistowski BM, Clyde CT, Parvizi J. The economics of using prophylactic antibiotic-loaded bone cement in total knee replacement. Bone Joint J. 2014;96-B:65-9. https://doi.org/10.1302/0301-620X.96B1.31428.

29. Thomas P, Schuh A, Summer B, Mazoochian F, Thomsen M. Allergy towards bone cement. Orthopade. 2006;35:956-60. https://doi.org/10.1007/s00132006-0981-3.

30. Pacheco KA. Allergy to surgical implants. J Allergy Clin Immunol Pract. 2015; 3:683-95. https://doi.org/10.1016/j.jaip.2015.07.011. 
31. Guenther D, Thomas P, Kendoff D, Omar M, Gehrke T, Haasper C. Allergic reactions in arthroplasty: myth or serious problem? Int Orthop. 2016:40:23944. https://doi.org/10.1007/s00264-015-3001-6.

32. Thomas B, Kulichova D, Wolf R, Summer B, Mahler V, Thomas P. High frequency of contact allergy to implant and bone cement components, in particular gentamicin, in cemented arthroplasty with complications: Usefulness of late patch test reading. Contact Dermatitis. 2015;73:343-9. https://doi.org/10.1111/cod.12465.

33. Edwards SA, Gardiner J. Hypersensitivity to benzoyl peroxide in a cemented total knee arthroplasty. Cement Allergy. J Arthroplast. 2007;22:1226-8. https://doi.org/10.1016/j.arth.2006.10.019.

34. Bircher A, Friederich NF, Seelig W, Scherer K. Allergic complications from orthopaedic joint implants: the role of delayed hypersensitivity to benzoyl peroxide in bone cement. Contact Dermatitis. 2012;66:20-6. https://doi.org/ 10.1111/j.1600-0536.2011.01996.x.

35. Kenan S, Kahn L, Haramati N, Kenan S. A rare case of pseudotumor formation associated with methyl methacrylate hypersensitivity in a patient following cemented total knee arthroplasty. Skelet Radiol. 2016;45:1115-22. https://doi.org/10.1007/s00256-016-2372-0.

36. Vega F, Bazire R, Belver MT, Mugica MV, Urquia A, Blanco C. Aseptic loosening of a total knee prosthesis caused by delayed hypersensitivity to bone cement. Ann Allergy Asthma Immunol. 2016;117:89-91. https://doi. org/10.1016/j.anai.2016.04.013.

37. Roos EM, Roos HP, Lohmander LS, Ekdahl C, Beynnon BD. Knee Injury and Osteoarthritis Outcome Score (KOOS) — development of a self-administered outcome measure. J Orthop Sport Phys Ther. 1998;28:88-96. https://doi.org/ 10.2519/jospt.1998.28.2.88.

38. Kessler S, Lang S, Puhl W, Stöve J. The Knee Injury and Osteoarthritis Outcome Score - a multifunctional questionnaire to measure outcome in knee arthroplasty. Z Orthop Ihre Grenzgeb. 2003;141:277-82. https://doi.org/ 10.1055/s-2003-40083.

39. Cheuy VA, Foran JRH, Paxton RJ, Bade MJ, Zeni JA, Stevens-Lapsley JE. Arthrofibrosis associated with total knee arthroplasty. J Arthroplast. 2017;32: 2604-11. https://doi.org/10.1016/j.arth.2017.02.005.

40. Scott CEH, Howie CR, MacDonald D, Biant LC. Predicting dissatisfaction following total knee replacement: a prospective study of 1217 patients. J Bone Joint Surg (Br). 2010;92:1253-8. https://doi.org/10.1302/0301-620X. 92B9.24394.

41. Bourne RB, Chesworth BM, Davis AM, Mahomed NN, Charron KDJ. Patient satisfaction after total knee arthroplasty: Who is satisfied and who is not? Clin Orthop Relat Res. 2010;468:57-63. https://doi.org/10.1007/s11999-009-1119-9.

42. Khan M, Osman K, Green G, Haddad FS. The epidemiology of failure in total knee arthroplasty: avoiding your next revision. Bone Joint J. 2016;98-B:10512. https://doi.org/10.1302/0301-620X.98B1.36293.

43. Australian Orthopaedic Association National Joint Replacement Registry (AOANJRR). Hip, Knee \& Shoulder Arthroplasty: 2019 Annual Report. Adelaide AOA 2019.

44. Grimberg A, Jansson V, Melsheimer O, SA. Jahresbericht 2019. Endoprothesenregister Deutschl 2019.

45. Hallock K, Vaughn N, Juliano P, Marks J. Metal hypersensitivity and orthopedic implants: survey of orthopedic surgeons. Dermatitis. 2017;28:7680. https://doi.org/10.1097/DER.0000000000000236.

46. Montkny E, Oleffe J, Donkerwolke M. Methylmethacrylate hypersensitivity in a patient with cemented endoprosthesis: a case report. Acta Orthop Scand. 1978;49:554-6. https://doi.org/10.3109/17453677808993237.

47. Jäger $M, B a l d a B R$. Loosening of a total hip prosthesis at contact allergy due to benzoyl peroxide. Arch Orthop Trauma Surg. 1979;94:175-8. https://doi. org/10.1007/BF00618442.

48. Haddad FS, Cobb AG, Bentley G, Levell NJ, Dowd PM. Hypersensitivity in aseptic loosening of total hip replacements. The role of constituents of bone cement. J Bone Joint Surg (Br). 1996;78-B:546-9. https://doi.org/10. 1302/0301-620X.78B4.0780546

49. Kaplan K, Della Valle CJ, Haines K, Zuckerman JD. Preoperative identification of a bone-cement allergy in a patient undergoing total knee arthroplasty. J Arthroplast. 2002;17:788-91. https://doi.org/10.1054/arth.2002.33571.

50. Alamri A, Lill D, Summer B, Thomas P, Thomas B, Oppel E. Artificial nail wearing: unexpected elicitor of allergic contact dermatitis, oral lichen planus and risky arthroplasty. Contact Dermatitis. 2019. https://doi.org/10.1111/cod.13250.

51. Treudler R, Simon JC. Benzoyl peroxide: is it a relevant bone cement allergen in patients with orthopaedic implants? Contact Dermatitis. 2007:57: 177-80. https://doi.org/10.1111/j.1600-0536.2007.01195.x.
52. Thomas P, Schuh A, Eben R, Thomsen M. Allergy to bone cement components. Orthopade. 2008;37:117-20. https://doi.org/10.1007/s00132008-1195-7.

53. Hausten U-F, Tegetmeyer $\mathrm{L}$, Ziegler $\mathrm{V}$. Allergic and irritant potential of benzoyl peroxide. Contact Dermatitis. 1985;13:252-7. https://doi.org/10. 1111/j.1600-0536.1985.tb02559.x.

54. Ockenfels H-M, Uter W, Lessmann H, Schnuch A, Geier J. Patch testing with benzoyl peroxide: reaction profile and interpretation of positive patch test reactions. Contact Dermatitis. 2009;61:209-16. https://doi.org/10.1111/j.16000536.2009.01603.x

55. Childs-Kean LM, Shaeer KM, Varghese Gupta S, Cho JC. Aminoglycoside allergic reactions. Pharmacy. 2019;7:124. https://doi.org/10.3390/ pharmacy7030124.

56. Menezes de Pádua CA, Uter W, Schnuch A. Contact allergy to topical drugs: prevalence in a clinical setting and estimation of frequency at the population level. Pharmacoepidemiol Drug Saf. 2007;16:377-84. https://doi. org/10.1002/pds.1268.

57. Liippo J, Lammintausta K. Positive patch test reactions to gentamicin show sensitization to aminoglycosides from topical therapies, bone cements, and from systemic medication. Contact Dermatitis. 2008;59:268-72. https://doi. org/10.1111/j.1600-0536.2008.01419.x.

58. Green CM, Holden CR, Gawkrodger DJ. Contact allergy to topical medicaments becomes more common with advancing age: an agestratified study. Contact Dermatitis. 2007:56:229-31. https://doi.org/10.1111/j. 1600-0536.2006.01084.x.

59. Haeberle M, Wittner B. Is gentamicin-loaded bone cement a risk for developing systemic allergic dermatitis? Contact Dermatitis. 2009;60:176-7. https://doi.org/10.1111/j.1600-0536.2008.01482.x.

60. Christiansen IS, Pedersen P, Krøigaard M, Mosbech H, Garvey LH. Anaphylaxis to intravenous gentamicin with suspected sensitization through gentamicin-loaded bone cement. J Allergy Clin Immunol Pract. 2016;4:1258-1259.e1. https://doi.org/10.1016/j.jaip.2016.07.003.

61. Wittmann D, Summer B, Thomas B, Halder A, Thomas P. Gentamicin allergy as an unexpected 'hidden' cause of complications in knee arthroplasty. Contact Dermatitis. 2018;78:293-4. https://doi.org/10.1111/cod.12930.

62. Garratt AM. Patient-assessed health instruments for the knee: a structured review. Rheumatology. 2004;43:1414-23. https://doi.org/10.1093/ rheumatology/keh362.

63. Collins NJ, Prinsen CAC, Christensen R, Bartels EM, Terwee CB, Roos EM. Knee Injury and Osteoarthritis Outcome Score (KOOS): systematic review and meta-analysis of measurement properties. Osteoarthr Cartil. 2016;24: 1317-29. https://doi.org/10.1016/j.joca.2016.03.010.

64. Ramkumar PN, Harris JD, Noble PC. Patient-reported outcome measures after total knee arthroplasty: a systematic review. Bone Jt Res. 2015;4:120-7. https://doi.org/10.1302/2046-3758.47.2000380

65. Theodoulou A, Bramwell DC, Spiteri AC, Kim SW, Krishnan J. The use of scoring systems in knee arthroplasty: a systematic review of the literature. J Arthroplast. 2016;31:2364-2370.e8. https://doi.org/10.1016/j.arth.2016.05.055.

\section{Publisher's Note}

Springer Nature remains neutral with regard to jurisdictional claims in published maps and institutional affiliations.

Ready to submit your research? Choose BMC and benefit from

- fast, convenient online submission

- thorough peer review by experienced researchers in your field

- rapid publication on acceptance

- support for research data, including large and complex data types

- gold Open Access which fosters wider collaboration and increased citations

- maximum visibility for your research: over $100 \mathrm{M}$ website views per year

At $\mathrm{BMC}$, research is always in progress.

Learn more biomedcentral.com/submissions 